\title{
Será preciso de novo falar de humanismo?*
}

Será de nuevo preciso hablar de humanismo?

Will it be accurante again to speak of humanism?

Fecha de entrega: 5 de noviembre de 2015

Fecha de evaluación: 5 de diciembre de 2015

Fecha de aprobación: 15 de enero de 2016

Marcelo Perine ${ }^{* *}$

\section{Resumo}

Esta comunicação toma como ponto de partida um conflito paradigmático entre as concepções de Isócrates e de Platão sobre a educação e o ideal de homem que as guiava, para esboçar os traços de outro conflito de entre o humanismo inspirado pela tradição grega, assumido e transformado no interior da tradição cristã, e um "humanismo" que, no quadro do pensamento liberal, tenta recriar o ideal de homem em termos de indivíduo isolado, com desdobramentos consequentes na concepção da sociedade e das tarefas do Estado. As três figuras do conflito aqui esboçadas indicam que os desafios atuais do humanismo

* DOI: http://dx.doi.org/10.15332/s0120-8462.2016.0114.02

* Profesor asociado de la PUC/SP de Brasil. Doctor en Filosofía de la Pontificia Universidad Gregoriana de Roma. Magister en Filosofía y Teologia. Graduación en Filosofía y Teologia (1980). Correo electrónico: mperine@gmail.com. Ha publicado numerosos libros y artículos en revistas cientificas internacionales. Sus temas principales de investigación son la filosofía práctica y filósofos antiguos como Platón y Aristótreles, campo de estudio del cual proviene el presente artículo. 
de inspiração cristã são certamente mais graves do que os que se apresentaram ao humanismo grego do século IV a. C. O individualismo assumido como ideologia, o liberalismo transformado em tradição e o neoliberalismo como doutrina econômica hegemônica configuram uma compreensão de homem e dos bens da vida humana, nas suas dimensões individuais e sociais, em contraste radical com a que se reporta à tradição cristã.

Palabras clave: humanismo, individualismo, liberalismo, bem comum, justiça.

\section{Resumen}

Esta comunicación toma como punto de partida un conflicto paradigmático entre las concepciones de Isócrates y de Platón sobre la educación y el ideal de hombre que las guiaba, para delinear los trazos de otro conflicto entre el humanismo inspirado por la tradición griega, asumido y transformado en el interior de la tradición cristiana, y un "humanismo" que, en el marco del pensamiento liberal, intenta recrear el ideal de hombre en términos de individuo aislado, con desdoblamientos consecuentes en la concepción de la sociedad y de las tareas del Estado. Las tres figuras del conflicto aquí expuestas indican que los desafíos actuales del humanismo de inspiración cristiana son ciertamente más graves de los que se le presentaron al humanismo griego del siglo IV a.c. El individualismo asumido como ideología, el liberalismo transformado en tradición y el neoliberalismo como doctrina económica hegemónica conforman una comprensión de hombre y de los bienes de la vida humana, en sus dimensiones individuales y sociales, en contraste radical con la que se reporta a la tradición cristiana.

Keywords: humanismo, individualismo, liberalismo, bien común, justicia. 


\section{Abstract}

This paper takes as its starting point a paradigmatic conflict between the views of Isocrates and Plato on education and the ideal of man that guided them to delineate the lines of another conflict between humanism inspired by the Greek tradition, taken and transformed within the Christian tradition, and a "humanism" that, in the context of liberal thinking, tries to recreate the ideal of man in terms of isolated individual, with the consequent unfolding in the conception of society and State tasks. The three figures of the conflict presented here indicate that the current challenges of humanism of Christian inspiration are certainly more serious than those of Greek humanism in the 4 th century B.C. Individualism assumed as an ideology, liberalism transformed into tradition and neoliberalism as an hegemonic economic doctrine make an understanding of man and goods of human life in their individual and social dimensions, in radical contrast to that reported to Christian tradition.

Palavras-chave: humanism, individualism, liberalism, common good, justice. 


\section{Um conflito de humanismos: Isócrates x Platão}

A expressão "conflito de humanismos", ponto de partida para a presente reflexão, é inspirada na obra de Enrico Berti sobre a filosofia do primeiro Aristóteles (Berti, 1997). O autor mostra que a rivalidade entre as diferentes concepções da educação, representadas por Isócrates e Platão, constituiu um verdadeiro conflito de humanismos, que ocupou o centro da vida cultural ateniense do século IV a. C.

O ponto de discórdia estava na concepção da educação ideal. Para Isócrates esta seria constituída pela retórica, ou seja, pela arte dos discursos, no seu entender a única capaz de exprimir os conteúdos ético-políticos necessários à formação dos jovens atenienses. Isócrates reivindicava para si o título de mestre de filosofia por considerar sua arte retórica como a verdadeira filosofia, contrariamente ao que pensava Platão, para quem a verdadeira filosofia chamava-se dialética, uma ciência com objeto e método próprios. Conforme observou Berti (1997):

\footnotetext{
Enquanto Platão na República prescreve aos seus futuros governantes, sobretudo o estudo da matemática, que serve para separar-se do mundo da experiência e para elevar-se ao inteligível, Isócrates, ao contrário, exorta Nicocles ao estudo da história, justamente porque este serve para adquirir uma grande experiência (p. 91).
}

Esta polêmica é evocada no início da minha reflexão por duas razões. Em primeiro lugar porque não se pode falar de humanismo sem fazer alguma referência a Isócrates, considerado por muitos como o pai da cultura humanística. É sintomático, como observou Werner Jaeger, que, a partir do Renascimento, Isócrates se tenha destacado mais que qualquer outro mestre da Antiguidade, influenciando enormemente a prática pedagógica do humanismo. Em segundo lugar porque, ainda segundo uma observação de Werner Jaeger, a dialética histórica do ideal de cultura que se desenrola no diálogo entre Platão e Isócrates, “apesar de todas as mesquinharias humanas da polêmica, encerra um valor permanente" (Jaeger, 1995, p. 1080). Com efeito, Jaeger sustenta que, para os educadores atuais, a essência do humanismo é, substancialmente, a continuação da linha retórica da cultura antiga e que a história do humanismo vai muito mais longe do que se pensa, pois abrange a totalidade das repercussões da paidéia grega. Escreve Jaeger: "encarada desta forma, a consciência da autêntica 
paidéia dos Gregos converte-se diretamente na autocrítica do humanismo erudito dos tempos modernos" (1995, p. 1062).

Sem precisar tomar partido no conflito entre Isócrates e Platão, a sua evocação pretende chamar a atenção para o fato de que qualquer reflexão sobre "a descoberta da humanidade" na nossa tradição de pensamento deve nos remeter a uma consideração sobre “a nossa posição perante os Gregos”, conforme o título de um estudo muito esclarecedor de Bruno Snell (1992) sobre as origens do humanismo ocidental. É justamente por isso que pretendo partir de uma breve consideração sobre dois pontos fundamentais do legado grego ao nosso humanismo, para refletir em seguida sobre três expressões de um conflito atual que, a meu ver, pode ser interpretado como um conflito de humanismos.

\section{0 legado grego ao nosso humanismo}

O primeiro ponto da herança grega em nosso humanismo para o qual chamo a atenção refere-se à ideia de homem, ao mesmo tempo matriz e produto da paidéia grega. Com efeito, foi uma ideia ou um ideal de homem que inspirou todo o conjunto de procedimentos práticos e teóricos constitutivos da genuína paidéia grega. De acordo com a aguda observação de Werner Jaeger, o específico da paidéia grega, em contraste com a forma de vida dos povos orientais, foi o fato de se ter constituído em torno de uma ideia de homem, isto é, em torno de uma imagem de homem genérico na sua validade universal e normativa, à qual aspiravam todos os educadores, poetas, artistas e filósofos. Os gregos adquiriram progressivamente a consciência de que o processo de educação consistia "na modelagem dos indivíduos pela norma da comunidade" (Jaeger, 1995, p. 15), em função de uma ideia ou ideal de homem que não se formou como esquema vazio, mas como forma viva gerada no espaço e no tempo a partir das realizações daquele povo.

Ora, a ideia de homem que se revela na paidéia grega é a do homem político, isto é, o homem sempre vinculado a uma comunidade constituída, ao mesmo tempo condição para a sobrevivência dos indivíduos e lugar do exercício efetivo do que os gregos designaram como a especificidade humana, a saber, sua capacidade discursiva. Neste sentido, as concepções de Platão e de Aristóteles a respeito da origem das cidades somam-se para apresentar o segundo ponto do legado grego ao nosso humanismo. No segundo livro da República, Platão recorre a um mito para descrever o surgimento 
das cidades, e afirma que elas nascem porque cada um de nós não é autossuficiente, mas necessitado de muitas coisas que só podem ser conseguidas com a ajuda dos outros (II, 369 a. C). No primeiro livro da Política, Aristóteles afirma que o homem é um "animal de cidade"1 (Cassin, 2000, p. 49), vale dizer, um animal produzido pela natureza com a capacidade de falar e de agir de acordo com essa capacidade discursiva e, acima de tudo, um animal capaz de se servir da palavra para formular noções universais como o bem e o mal, o justo e o injusto, o útil e o danoso, cuja posse comum constitui a família, primeira expressão da natureza política do homem, e a cidade, expressão mais elevada da sua naturalidade política (I, 2, 1253 a 6-16).

Subjacente à explicação mítica da origem das cidades em Platão estão os dados antropológicos da incapacidade original de prover sozinho à própria subsistência e da capacidade de estabelecer laços cooperativos para adquirir os bens comuns que venham a garantir a sobrevivência de todos. Do mesmo modo, na afirmação aristotélica de que a posse comum de noções universais é o que está na origem da família e da cidade, encontra-se o dado antropológico da capacidade de criar relações de igualdade e de agir em conjunto segundo normas ou noções universais partilhadas. Portanto, a dimensão política da ideia grega de homem é afirmada como natural, revelando-se, por um lado, a partir das necessidades de conservação e desenvolvimento da própria vida física e, por outro, a partir da habilidade para estabelecer relações e empreender ações em conjunto, de acordo com procedimentos próprios da vida associada.

A ideia de homem e a ideia de cidade estão, portanto, profundamente vinculadas na cultura grega, e o vínculo entre elas é estabelecido pela educação. Com efeito, era pela educação que se podia fazer com que as capacidades naturais se tornassem possibilidades realizadas, vale dizer, era a educação que permitia que uma concepção da natureza humana em estado bruto pudesse ser conduzida a uma ideia da natureza humana tal como ela poderia ser se realizasse o seu ideal, isto é, o seu télos (MacIntyre, 1985, p. 51).

A concepção teleológica da natureza humana se traduzia, em termos de compreensão da sociedade, na ideia de bens partilhados e de bens de excelência, juntamente com a ideia de justiça de merecimento que regia as relações no interior da comunidade.

1 A tradução da Política aqui utilizada é a de A. Campelo Amaral e C. de Carvalho Gomes, na edição bilingue publicada em 1998 pela Editora Veja de Lisboa. Entretanto, a expressão "animal de cidade" para traduzir o grego ánthropos phúsei politikòn zòon foi extraida de: CASSIN, B. Aristóteles e o Logos. Contos da fenomenologia comum. 
Essa concepção informava uma compreensão da sociedade segundo o modelo predominantemente cooperativo, muito embora também se encontrem no pensamento de Platão e de Aristóteles traços do que virá a ser o modelo conflitivo de compreensão da sociedade (Höffe, 1991). Esta observação pretende simplesmente afirmar que a predominância, na antropologia política e na sociologia modernas, de uma concepção do homem como ser de conflito, mais do que de cooperação, não torna obsoleta a concepção clássica do homem, da qual decorre uma compreensão da sociedade como comunidade moral estruturada em torno de noções universais, de bens partilhados e de justiça.

São estes os dois pontos que destaco neste momento, com vistas à reflexão que pretendo desenvolver em seguida sobre três facetas da crise contemporânea na qual, acredito, está em jogo um conflito de humanismos: um que se reporta ao legado grego e se empenha em revitalizá-lo diante dos novos desafios propostos pela nossa contemporaneidade, o outro que pretende responder a estes mesmos desafios a partir de outra ideia de homem e de sociedade.

\section{0 conflito atual de humanismos}

Apresento agora, brevemente, três expressões de um conflito atual que pode ser caracterizado como um conflito de humanismos. Vou me referir, em primeiro lugar, ao conflito em torno da ideia de homem; em segundo lugar, ao conflito em torno da concepção da sociedade e, finalmente, ao conflito em torno da tarefa fundamental do Estado.

\section{a. Indivíduo versus cidadão}

Grande parte dos críticos da modernidade está de acordo em afirmar que o individualismo se transformou na ideologia dominante do nosso tempo. Já nos anos 1930, Emmanuel Mounier, juntamente com o grupo Esprit, se empenhava em distinguir entre o personalismo e o individualismo, a pessoa e o indivíduo, definindo a pessoa como uma capacidade de se descentrar para se tornar disponível ao outro, e o indivíduo como um mundo fechado cujo único interesse consiste em reivindicar suas seguranças egoístas. Mounier chegou mesmo a afirmar que o individualismo não era apenas uma moral, mas acima de tudo uma "metafísica da solidão integral, 
a única que nos resta quando perdemos a verdade, o mundo e a comunidades dos homens" (1963, p. 158).

Considerado como uma moral, o individualismo se inscreve, por um lado, na linha de continuidade do movimento filosófico desencadeado pelo Iluminismo europeu e, por outro, no interior do Liberalismo como tradição de pensamento político que, a partir do século XIX, pretendeu ser uma alternativa ao pensamento republicano (Petit, 1996). Segundo Alasdair MacIntyre, o grande projeto do Liberalismo de criar uma ordem social na qual os indivíduos se emancipassem da contingência e da particularidade da tradição, pelo recurso a normas genuinamente universais e independentes dela, não foi uma invenção de filósofos, mas da sociedade liberal moderna e individualista.

Uma das novidades do projeto liberal consistiu em difundir uma nova mentalidade que concebia os bens humanos exclusivamente em termos de preferências pessoais expressas em primeira pessoa, formuladas como razões para agir. A generalização desta mentalidade ocorreu em harmonia com os procedimentos dos domínios públicos do mercado e da política individualista liberal, de modo que esses novos procedimentos no domínio público, aliados à nova mentalidade no domínio privado, acabou definindo um novo artefato social e cultural, que é 'o indivíduo', um ser que só raciocina como indivíduo, vale dizer, motivado exclusivamente por suas preferências pessoais.

Intimamente ligada a esta concepção do pensamento e da ação moral, está a concepção liberal da ordem justa, cujo bem supremo se reduz à manutenção continuada da ordem social e política liberal. A astúcia do Liberalismo estaria na sua capacidade de ocultar aos nossos olhos que os argumentos oferecidos por ele em favor da sua concepção dos bens humanos só são decisivos num horizonte moral totalmente desprovido de qualquer concepção finalista do bem e, consequentemente, de qualquer concepção de um bem supremo ${ }^{2}$.

2 Estas reflexões baseiam-se no capitulo XVII, "Liberalism Transformed into a Tradition" do livro de: MACINTYRE, A., Whose Justice? Which Rationality?, Notre Dame, University of Notre Dame Press, 1988, p. 326-348. Sobre esta obra ver: PERINE, M. "Virtude, justiça, racionalidade. A propósito de Alasdair Maclntyre", Sintese Nova Fase, 19(58), 391-412, jul./set. 1992. Uma brilhante exposição do pensamento de MacIntyre encontra-se em: CARVALHO, H. B. A. de. Tradição e racionalidade na filosofia moral de Alasdair MacIntyre, Teresina, EDUFPI, 2. ${ }^{\text {ed. }}$ revista, 2011. 
Ora, o que temos aqui é um verdadeiro conflito de humanismos: por um lado o que se reporta ao legado dos gregos na origem da nossa tradição cultural e, por outro, a nova concepção do homem forjada no interior da recente tradição liberal. Com efeito, parece-me que são dois modos radicalmente opostos de conceber o ser humano e seu modo de raciocinar com vistas à ação: num deles o indivíduo raciocina exclusivamente como indivíduo, no outro raciocina como cidadão; num deles o indivíduo interpreta seus bens em termos de preferências pessoais, no outro busca seu bem no horizonte de um bem comum partilhado com a comunidade à qual está vitalmente ligado por laços de dependência e cooperação, ao mesmo tempo que pela posse comum de noções universais como as de bem e de justiça.

\section{b. Comunidade moral versus sociedade global}

Quer estabeleçamos a origem da sociedade moderna na passagem das economiasmundo para a economia mundial (Braudel, 1996), quer fixemos o seu nascimento no bojo da grande crise espiritual que abalou a Europa no século XVII (Mousnier, 1960), quer, ainda, tomemos como ponto de referência a Revolução Industrial que se inicia na Inglaterra a partir de 1750 , o que permite aplicar à nossa sociedade o adjetivo "moderno" é o desenvolvimento de uma nova forma do trabalho social que, por força do seu princípio, se contrapõe radicalmente à antiga forma do trabalho social. O que distingue a moderna forma do trabalho social é o fato de se ter tornado universal, de modo que a sua técnica é a mesma em todas as sociedades consideradas modernas. É evidente que a universalização da nova forma do trabalho social não pode ser compreendida como um epifenômeno do capitalismo industrial, mas como a expressão material da sua lógica interna ${ }^{3}$.

O trabalho social moderno se tornou o sagrado da sociedade moderna (Weil, 2011). Ora, esse novo sagrado é cultuado na sociedade moderna sob a forma de uma "trindade". Com efeito, a sociedade moderna, em primeiro lugar, é calculista, pois tudo nela é justificado por meio de um cálculo que demonstre a ampliação do domínio do homem sobre a natureza. A sociedade moderna, em segundo lugar, é materialista, porque nas decisões tomadas no seu interior só os fatores materiais são levados em conta. Finalmente, a sociedade moderna é mecanicista porque todos os problemas que surgem no seu interior devem ser transformados em problemas de método de

3 Sobre o desenvolvimento do capitalismo na Europa ver: Hobsbawwn, E. J. A era do capital - 18481875, trad. de L. Costa Neto, Rio de Janeiro, Paz e Terra, 2. ${ }^{\text {e ed., }} 1979$. 
trabalho e de organização segundo as regras de funcionamento da sociedade, entendida como um mecanismo social.

No interior dessa sociedade o produto social é distribuído de maneira desigual, mas o mecanismo social age sempre da mesma maneira sobre os indivíduos, obrigandoos a pôr à disposição da sociedade todas as suas forças físicas e/ou intelectuais. A competição se torna a "regra de ouro" da sociedade, obrigando os indivíduos a não fazer aos outros o que eles gostariam que os outros lhes fizessem. Na competição pela participação no produto social, os indivíduos devem se considerar como objetos a serem valorizados e devem atribuir-se o mais alto grau possível de utilidade. A regra de conduta imposta aos indivíduos é confirmada pelo sucesso, enquanto o fracasso fica sob a responsabilidade do indivíduo, pelo fato de não ter seguido ou não ter podido seguir a regra de conduta válida no interior do mecanismo social. Para a sociedade, pouco importa se o indivíduo podia ou não podia seguir a "regra de ouro" da sociedade. O único princípio absolutamente inquestionável que rege a vida dos indivíduos na sociedade é o da eficácia.

Esta imagem da sociedade moderna, aqui sumariamente descrita, sofreu sensíveis transformações após a Segunda Guerra Mundial, em consequência da progressiva imposição do modelo neoliberal a partir dos centros de poder do capitalismo avançado 4 . A lógica do modelo neoliberal não é mais que um refinamento da lógica da eficácia, que comandou o processo de modernização das sociedades ocidentais. Quando o fundador do neoliberalismo, Friedrich von Heyek, afirmou que a desigualdade era um valor positivo, até mesmo imprescindível, do qual as sociedades ocidentais estavam carentes; ou quando reconheceu que a democracia em si mesma nunca tinha sido um valor central do neoliberalismo, ele estava simplesmente contribuindo para a transformação da lógica imanente ao moderno mecanismo social em movimento ideológico de escala mundial, pela transformação daquela lógica em "corpo de doutrina coerente, autoconsciente, militante, lucidamente decidido a transformar todo o mundo à sua imagem, em sua ambição estrutural e sua extensão internacional" (Anderson, 1995, p. 22).

Segundo o economista Gabriele Muzio (1999), um dos mais refinados produtos da ideologia neoliberal é o processo de globalização da economia atualmente em curso.

4 Retomo aqui, de maneira reduzida, uma reflexão mais extensa desenvolvida em: Perine, M. Esperando Godot ou um novo São Bento? Filósofos, 4(2), 171-204, jul./dez. 1999, espec. pp. 179-182. 
No centro deste processo encontram-se dois conceitos fundamentais para a compreensão do fenômeno: o de escala e o de utilidade individual, que devem ser considerados em conjunto (p. 136). Em primeiro lugar, porque os dois conceitos se baseiam na ideia de quantificação como único indicador para medir o sucesso individual e o do sistema como um todo. Em segundo lugar, porque a ideia de utilidade se tornou o fundamento de um sistema unificado de preferências constituído exclusivamente por bens materiais tangíveis, que não admite alternativas.

Se confrontarmos estas observações com as que fiz acima sobre a nova concepção do indivíduo e sobre o individualismo produzido pela ideologia liberal, bem como sobre a "trindade" dominante na sociedade moderna - o cálculo, a matéria e o mecanismo-, torna-se evidente que o processo de globalização, cujas características mais salientes são a homogeneização do mundo e a glorificação da tecnologia, representa "a realização acabada e a perfeição do projeto de modernidade e de seu paradigma de progresso" (Muzio, 1999, p. 139).

No meu entender, também aqui nos encontramos diante de um conflito de humanismos, dado que estão subjacentes a esse processo uma ideia de homem e uma concepção da sociedade humana. Em primeiro lugar porque as ideias de quantificação e de utilidade, que estão no centro da ideologia neoliberal, obrigam a pensar que tudo o que não puder ser reduzido a bens materiais de consumo não poderá ser incluído no sistema unificado de preferências fundado, justamente, sobre aquelas ideias de utilidade e de quantidade. Assim, segundo a lógica implacável da ideologia neoliberal, as motivações, individuais e grupais, provenientes de um sistema de crenças ou de um sistema de valores morais não quantificáveis estão condenadas senão à extinção, pelo menos à impossibilidade de dirigir a ação humana.

Além da desvalorização de tudo o que não é quantificável ou utilitário, a homogeneização do mundo decorrente do processo de globalização é acompanhada pelo menosprezo a tudo o que for local, particular ou regional, considerados como incapazes de se adequar à concepção global atualmente dominante. Portanto, a ação conjunta dos conceitos de utilidade e de escala acaba provocando, senão a eliminação, pelo menos a marginalização de tudo o que resiste à redução do mundo a uma visão global unificada. Ora, o local, o particular, o regional, numa palavra, tudo o que se refere à moral e à tradição das comunidades humanas não tem lugar num mundo que avalia a realidade unicamente em termos de escala. 
Estamos diante de um conflito de humanismos porque a força propulsora do caráter tecnológico da globalização é, ainda segundo Gabriele Muzio, “a ideologia da onipotência, baseada na crença na capacidade ilimitada da tecnologia desenvolvida pelo homem de superar qualquer obstáculo" (1999, p. 139). Ora, a ideologia da onipotência está na origem da atitude agressiva, dominadora e predatória da natureza, que caracteriza as sociedades modernas submetidas ao domínio da tecnociência. Para os que não sucumbiram ao pseudo-humanismo da ideologia dominante, a questão que se coloca é a mesma que, segundo Lima Vaz, se levanta no horizonte filosófico na aurora do século XXI, a saber, a pergunta se a tecnociência, transformada em norma regente do nosso existir, poderá acolher e explicar as dimensões não quantificáveis da vida humana, como as que se revelam na experiência religiosa ou na experiência moral da humanidade ${ }^{5}$.

\section{c. Eficácia versus justiça}

Finalmente, nos diferentes modos de compreender e resolver o problema fundamental do Estado moderno também subjaz um conflito de humanismos. Esse problema foi formulado com grande lucidez por Éric Weil em termo de exigência de conciliação do justo com o eficaz, isto é, da moral viva da comunidade com a racionalidade que se impôs na sociedade, e exigência de conciliar a justiça e a eficácia com a razão, entendida como "possibilidade de uma vida sensata para todos, que seja compreendida como tal por todos" (Weil, 2011, p. 238) ${ }^{6}$.

O que se vê na maioria dos países latino-americanos nas últimas décadas é uma clara opção pela lógica da eficácia e um escandaloso menosprezo pelas exigências da justiça. A adoção de políticas de caráter abertamente neoliberal levou ao que Robert Kurz chamou de "totalitarismo econômico", que "nada mais é do que a própria essência do liberalismo" (Kurz, 1999, p. 9). A aviltante submissão do político ao econômico, bem como a redução do econômico aos conceitos de escala e de utilidade, cujo único fim é a acumulação sem fim, traduzem a escandalosa inversão entre meios e fins e até mesmo a perda da noção de fim no horizonte da vida humana individual e social.

5 A este respeito ver: LIMA VAZ, H. C. de, "Presença de Tomás de Aquino no horizonte filosófico do século XXI", Sintese Nova Fase, 25(80), 19-42, jan./mar. 1998, partic. pp. 29-34.

60 desenvolvimento completo da tese de Weil está nas, pp. 238-298. 
É evidente que as respostas à exigência de conciliação da eficácia com a justiça serão diferentes, e até mesmo opostas, em função das ideias de homem e de sociedade humana subjacentes às concepções de políticas econômicas e sociais. É evidente que a conciliação do justo com o eficaz será diferente, segundo se tenha uma concepção do desenvolvimento como liberdade, para evocar aqui o título de um dos livros do Prêmio Nobel de economia, Amartya Sen (2000), ou uma concepção do desenvolvimento como processo de concentração de riqueza em benefício de uma minoria que, para manter um estilo de vida calcado no dispêndio crescente de recursos não renováveis, submete a maioria da humanidade a formas degradantes de exclusão das mais elementares condições de sobrevivência.

Um parágrafo extraído do capítulo sobre a "Nova concepção do desenvolvimento" do livro Brasil, a construção interrompida de Celso Furtado (1992) traduz brilhantemente o conflito de humanismos subjacente aos diferentes modos de resolver a exigência de conciliação da justiça com a eficácia.

O desafio que se coloca no umbral do século XXI é nada menos do que mudar o curso da civilização, deslocar o seu eixo da lógica dos meios a serviço da acumulação, num curto horizonte de tempo, para uma lógica dos fins em função do bem-estar social, do exercício da liberdade e da cooperação entre os povos. Devemos nos empenhar para que essa seja a tarefa maior dentre as que preocuparão os homens no correr do próximo século: estabelecer novas prioridades para a ação política em função de uma nova concepção do desenvolvimento, posto ao alcance de todos os povos e capaz de promover o equilíbrio ecológico. O objetivo deixaria de ser a reprodução dos padrões de consumo das minorias abastadas para ser a satisfação das necessidades fundamentais do conjunto da população e a educação concebida como desenvolvimento das potencialidades humanas nos planos ético, estético e da ação solidária. A criatividade humana, hoje orientada de forma obsessiva para a inovação técnica a serviço da acumulação econômica e do poder militar, seria dirigida para a busca da felicidade, esta entendida como a realização das potencialidades e aspirações dos indivíduos e das comunidades vivendo solidariamente (p. 76).

A esta penetrante análise de um dos mais destacados economistas brasileiros, feita no início dos anos 1990, fazem eco, quase vinte e cinco anos depois, as palavras de Papa Francisco na Carta Encíclica Laudato Si'(2009). Peço a benevolência do ouvinte 
para citar quase na íntegra o número 109 do capítulo III, intitulado "Raiz humana da crise ecológica”. Escreve o Papa Francisco:

O paradigma tecnocrático tende a exercer o seu domínio também sobre a economia e a política. A economia assume todo o desenvolvimento tecnológico em função do lucro, sem prestar atenção a eventuais consequências negativas para o ser humano. [...] Não se aprendeu a lição da crise financeira mundial e, muito lentamente, se aprende a lição do deterioramento ambiental. Nalguns círculos, defende-se que a economia atual e a tecnologia resolverão todos os problemas ambientais, do mesmo modo que se afirma [...] que os problemas da fome e da miséria no mundo serão resolvidos simplesmente com o crescimento do mercado. [...]. Aqueles que não o afirmam em palavras defendem-no com os fatos, quando parecem não se preocupar com o justo nível da produção, uma melhor distribuição da riqueza, um cuidado responsável do meio ambiente ou os direitos das gerações futuras. Com os seus comportamentos, afirmam que é suficiente o objetivo da maximização dos ganhos. Mas o mercado, por si mesmo, não garante o desenvolvimento humano integral nem a inclusão social $^{7}$. Entretanto temos um 'superdesenvolvimento dissipador e consumista que contrasta, de modo inadmissível, com perduráveis situações de miséria desumanizadora, ${ }^{8}$ mas não se criam, de forma suficientemente rápida, instituições econômicas e programas sociais que permitam aos mais pobres terem regularmente acesso aos recursos básicos. Não temos suficiente consciência de quais sejam as raízes mais profundas dos desequilíbrios atuais: estes têm a ver com a orientação, os fins, o sentido e o contexto social do crescimento tecnológico e econômico (p. 109).

\section{Concluindo}

A presente reflexão partiu de um conflito paradigmático entre as concepções de Isócrates e de Platão da educação ideal e da ideia de homem que a devia orientar. Ao final deste percurso, creio ter apontado indícios de outro conflito no qual se defrontam um humanismo inspirado na herança grega, assumida e transformada no

7 Cf. Bento XVI, Carta enc. Caritas in veritate (29 de junho de 2009), 35: AAS 101 (2009), 671.

8 Ibid., 22: o. c., 657. 
interior da tradição cristã, e um pseudo-humanismo que pretendeu recriar a ideia de homem em termos de indivíduo, no interior da tradição liberal, com os consequentes desdobramentos na concepção da sociedade e das tarefas do Estado.

As três figuras do atual conflito de humanismos, esboçadas nesta reflexão, indicam que os desafios que se apresentam ao humanismo de inspiração cristã são, certamente, maiores do que os enfrentados pelo humanismo grego do século IV a. C. O individualismo como ideologia, o liberalismo transformado em tradição e a ideologia neoliberal em escala global representam uma compreensão do homem e dos bens da vida humana radicalmente oposta ao humanismo cristão.

O que está em jogo nesse conflito não é apenas a sobrevivência de uma tradição de pensamento. Dependendo da direção em que se resolva o atual conflito de humanismos, ainda se poderá falar de cidadãos, de relações cooperativas, de bens partilhados, de comunidades morais, de ideais de justiça e de felicidade como a realização das potencialidades e aspirações de indivíduos e comunidades vivendo solidariamente. Caso contrário, será preciso aceitar a dominação dos novos bárbaros, que já não espreitam nossas fronteiras, mas nos governam há muito tempo. 


\section{Referencias}

Anderson, P. (1995). Balanço do neoliberalismo. Sader, E. e Gentilli, P. (Orgs.), Pósneoliberalismo. As políticas sociais e os Estado democrático, 22.

Aristoteles. (1253). Política. I, 2, 1253 a 6-19.

Bento, XVI. (2009, 29 de junhio). Carta enc. Caritas in veritate, 35: AAS 101 (2009).

Berti, E. (1997). La filosofia del "primo" Aristotele (Seconda edizione ed.). Milão: Vista e Pensiero.

Braudel, F. (1996). Civilização material, economia e capitalismo. Séculos XV-XVIII.O Tempo do Mundo. Em M. Stahel (Ed.). São Paulo: Martins Fontes.

Cassin, B. (2000). Aristóteles e o Logos. Contos da fenomenologia comum. (L. P. Rouanet, Trad.). São Paulo: Edições Loyola.

Furtado, C. (1992). Brasil, a construção interrompida (Tercera ed.). Rio de Janeiro: Paz e Terra.

Höffe, O. (1991). Justiça política. Fundamentação de uma filosofia do direito e do Estado. (E. Stein, Trad.). Petrópolis: Vozes.

Jaeger, W. (1995). Paidéia. A formação do homem grego. (M. Pereira, Trad.). São Paulo: Martins Fontes.

Kurz, R. (1999, 22 de agosto). Totalitarismo econômico, Caderno Mais! Folha de S. Paulo, p. 9.

MacIntyre, A. (1985). After virtue. A study in Moral Theory (Segunda ed.). Londres: Duckworth.

Macintyre, A. (1988). Liberalism Transformed into a Tradition. Em Whose Justice? Which Rationality? (pp. 326-348). Notre Dame: University of Notre Dame Press.

Mounier, E. (1963). Oeuvres I. Paris: Éd. du Seuil.

Mousnier, R. (1960). História Geral das Civilizações, tomo IV. Os séculos XVI e XVII. São Paulo: Difusão Europeia do Livro. 
Muzio, G. (1999). A globalização como estágio de perfeição do paradigma moderno: uma estratégia possível para sobreviver à coerência do processo. Oliveira, F.; Paoli, M. C. (Orgs.). Os sentidos da democracia. Políticas do dissenso e hegemonia global, 133-161.

Petit, P. ( 1996). Libéralisme, Dictionnaire d'éthique et de philosophie morale, sous la direction de Monique Canto-Sperber. Paris: PUF.

Platão. (369). República. II, 369 a. C.

Sen, A. (2000). Desenvolvimento como liberdade. (L. Teixeira Motta, Trad.). Sao Paulo: Companhia das Letras.

Snell, B. (1992). A descoberta da humanidade e a nossa posição perante os gregos. Em B. Snell, A descoberta do espírito (A. Morão, Trad., pp. 325-342). Lisboa: Edições 70.

Weil, E. (2011). Filosofia política. (M. Perine, Trad.). São Paulo: Edições Loyola, 2. ed. revista. 